\section{PRACTICAL NEUROLOGICAL DIAGNOSIS}

By R. Glen Spurling. Pp. xi 233. Figs. 99. Size $6 \times 9 \frac{1}{2}$. Bailliere, Tindall \& Cox. 1936. Price 18/-.

This is a readable and commonsense presentation of the methods of examination of the nervous system. The scope includes not only the usual clinical procedures, but also an account of such diagnostic aids as radiography, examination of the cerebrospinal fluid, and ventriculography. Dr. Spurling modestly disclaims any originality as to the subject-matter, except in the matter of arrangement and perhaps of interpretation. Many of the diagrams are borrowed from other sources, but all of them are clear and comprehensible. The book is well printed and attractive in its format.

\section{FAVOURITE PRESCRIPTIONS.}

Edited by Sir Humphrey Rolleston, BT., G.C.V.O., K.C.B., M.D., and AlaN MONCRIEFF, M.D., F.R.C.P.

Eyre and Spottiswoode. 1936. Price 10/6d.

A hospital pharmacopœia is hardly a text calculated to excite the enthusiasm of the medical author. Yet in Favourite Prescriptions no fewer than eighteen pens, under the influence of an editorial invitation and stirred presumably by local patriotism, have devoted themselves to the presentation of the virtues of the formulas which are enshrined in the pages of the corresponding hospital pharmacopœias. The writers be it admitted have made the best of their several texts; indeed they deserve the tribute that they have produced chapters of interest out of distinctly unpromising material. Whether the total result is worth all the trouble taken to achieve it is open to doubt. The hospital pharmacopœia is at its best a mixed document and represents habit and convenience rather than scientific prescribing. Yet tradition has its values, and if the old polypharmacy has lost its pride of place the modern tablet and the ready-made prescription are not prescribing at its best. Hence while in the present volume there are formulas which may excite surprise, and even less polite emotions, certain of the prescriptions have the testimony of the personal experience of recognised exponents of the prescribing art, while there are occasional practical hints on methods of treatment that are well worth noting. Opinions will differ as to the number of needles to be discovered in the haystack, but, to put the position at its lowest, while there is much hay there are certainly some needles.

\section{THE PRACTICE OF IONIZATION.}

By J. Newton Dyson, M.R.C.S. (Eng.), L.R.C.P. (Lond.). With a Foreword by Elkin P. Cumberbatch, M.A., B.M. (Oxon), D.R.M.E. (Cantab.), F.R.C.P. Pp. 176. Small 8vo. Henry Kimpton. Price 6/-.

This is a most useful little book because it clearly shows the practitioner how, at a very small cost, he may add greatly to his therapeutic resources.

The first three chapters are devoted to a consideration of the continuous current and definitions of the various electrical terms that are used in connection therewith, are given. Reference is also made to the different kinds of apparatus and the methods of their application. It is pointed out that the necessary apparatus is inexpensive both in outlay and upkeep and that most makers of electrical instruments supply a combined outfit containing all requirements at the cost of a few pounds.

The fourth chapter deals with ionization or the movement of ions which takes place in an electrolyte as the result of the passage of the galvanic current through it. The view that chemical ions can be introduced into the deeper tissues of the body, there to exert their therapeutic effects, finds no favour in the eyes of the writer. He quotes several experiments which appear to prove conclusively that a formerly widely spread belief is no longer tenable.

$\mathrm{He}$ does however hold that, although the ions of chemicals cannot be introduced by the constant current deeper than the skin, the action of certain chemicals is frequently made use of in ionization for their local effects on the skin and superficial tissues. This is exemplified by the pearly appearance of the surface of an ulcer after zinc 